\title{
Proline as a charge stabilizing amino acid in peptide radical cations
}

\author{
Nicolas P.-A. Monney ${ }^{\mathrm{a}}$, Thomas Bally ${ }^{\mathrm{a} *}$ and Bernd Giese ${ }^{\mathrm{a} *}$
}

\begin{abstract}
Long distance electron transfer in proteins requires relay stations that can be transitorily oxidized or reduced. Although individual prolines cannot assume this function, because of their high ionization energy, it has been shown that polyprolines have the ability to transfer charges. In order to determine the role of the proline in the hole distribution and transport within a PheProPhe tripeptide, the radical cation of a model compound where the phenylalanines carry two or three methoxy groups, respectively, was generated by flash photolysis. Surprisingly, after equilibration, about two thirds of the holes were found to reside on the phen $(\mathrm{OMe})_{2}$ instead of the more easily oxidizable phen $(\mathrm{OMe})_{3}$ moiety. DFT calculations showed that, in most of the accessible conformations, the phen $(\mathrm{OMe})_{2}^{+}$-moiety profits more from stabilization by $\mathrm{N}$ - and/or $\mathrm{O}$-lone pairs of neighboring amide groups than the phen $(\mathrm{OMe})_{3}^{+}$moiety can, which explains the apparently counterthermodynamic hole distribution. Similar calculations showed that, in several conformers of the natural PheProPhe radical cation, the unpaired electron is delocalized over two amide groups, by residing in a $\sigma \mathrm{MO}$ which links the $\mathrm{N}$-lone pair of the central proline unit with the $\mathrm{O}$-lone pair of a proximate amino acid, through hyperconjugation via the intervening $\mathrm{C}-\mathrm{C}_{\alpha} \sigma$-bond. The same pattern is found in a model compound, $\mathrm{N}$-acetylproline dimethylamide. It seems that prolines favor conformers which foster hyperconjugation of two amide groups, which lowers the ionization energy of peptides. One should thus consider such interacting amide groups as potential relay stations in the course of electron transfer in polyprolines.
\end{abstract}

Keywords: electron transfer; peptides; laser flash photolysis; DFT calculations

\section{INTRODUCTION}

An important function of peptides and proteins in living organisms is the transport of electrons or electron holes over long distances. ${ }^{[1]}$ Biopolymers connect electron donors (D) and electron acceptors (A) and mediate redox reactions between them. Because ET rates decrease exponentially with the D--A distance, ${ }^{[2]}$ single step (superexchange) electron transfer (ET) over more than $2 \mathrm{~nm}$ is too slow to occur through peptides and proteins in water. ${ }^{[3]}$ Nevertheless long distance ET takes place in proteins if it occurs by a multistep hopping process that proceeds via relay stations. ${ }^{[4]}$ In this way a long and therefore slow ET reaction can be divided into several short and therefore rapid steps. The electron/hole diffuses through the peptide using selected sites as hopping stations where it can reside for a short timespan. ${ }^{[5]}$ An important feature of the hopping mechanism is that overall electron/hole rates decrease only slightly with the total length of the peptide between the donor and the acceptor. ${ }^{[5,6]}$

Tyrosine, tryptophan and imidazole, which carry aromatic side chains with low oxidation and reduction potentials, respectively, may serve as potential relay stations. In the case of electron holes, the easily ionizable $\mathrm{S}$ lone pairs of cysteine and methionine may also serve as potential stepping stones, ${ }^{[7]}$ provided that the methionine radical cation is stabilized by a nearby amide $^{[8 \mathrm{a}]}$ or an aromatic residue. ${ }^{[8 \mathrm{~b}-\mathrm{d}]}$ In addition, it seems that the backbones of $\alpha$-and $31^{-}$as well of polyprolinehelices may also become stepping stones for ET hopping. ${ }^{[6,9]}$ The dipole moments of long $\alpha$-and $3_{10}$-helices are so large that they considerably reduce the oxidation potentials of amide groups. However, the dipole moments of polyproline-helices are too small to stabilize amide radical ions. ${ }^{[4 b, 10]}$ Thus, the question remains why and how proline can act as a relay amino acid in ET hopping reactions. In this paper we explore how an electron hole on the side chains of a model tripeptide composed of a tri- and a dimethoxy substituted phenylalanine linked by a proline can be stabilized by interaction with neighboring amide groups and how the hole can even be stabilized exclusively by the peptide backbone in the absence of side-chains that can serve as stepping stones.

\section{EXPERIMENTAL AND COMPUTATIONAL METHODS}

Solutions of $1(0.3-8 \mathrm{mM})$ were degassed in a quartz cell of $4.5-\mathrm{cm}^{-1}$ path length and irradiated with laser pulses (Lambda-Physik COMPex 205, I= $308 \mathrm{~nm}$, pulse width of $25 \mathrm{~ns}, 100-150 \mathrm{~mJ}$ per pulse) at RT $\left(22-24^{\circ} \mathrm{C}\right)$. An iStar 720 ICCD camera (Andor) was used for the detection of transient absorption spectra. Transient

\footnotetext{
* Correspondence to: T. Bally and B. Giese, University of Fribourg, Chemin du Musée 9, CH-1700 Fribourg, Switzerland.

E-mail: thomas.bally@unifr.ch; bernd.giese@unifr.ch

a N. P.-A. Monney, T. Bally, B. Giese

University of Fribourg, Chemin du Musée 9, CH-1700 Fribourg, Switzerland
} 


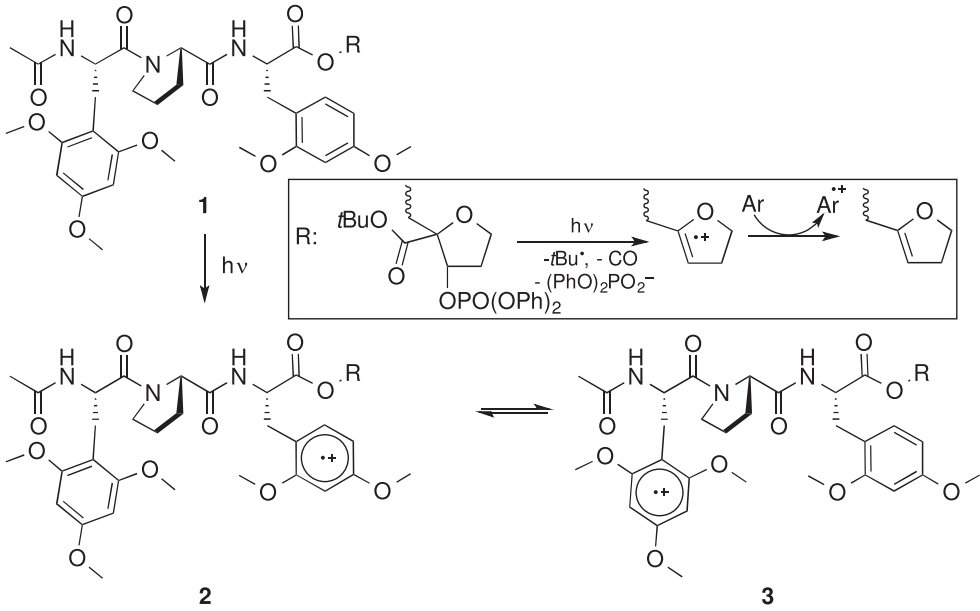

Scheme 1. Formation of radical cation $\mathbf{2}$ and equilibration with its 'electromer' 3. plemented in Gaussian. To model photoelectron spectra, vertical ionization energies were calculated as energy differences between the neutral and the ionized forms of a compound while excited states of radical cations were calculated, relative to the ground state, by TD-DFT.

\section{RESULTS AND DISCUSSION}

To identify the influence of a proline on the localization of an electron hole in a peptide, we recently synthesized the tripeptide $\mathbf{1}^{[19]}$ which contains a central proline that is bound at both ends to phenylalanines carrying $n=2$ or 3 methoxy groups, phe $(\mathrm{OMe})_{n}$. A radical cation was generated by laser induced fragmentation $^{[19]}$ (Scheme 1), and the electron hole was irreversibly transferred to the proximate phe(OMe) moiety, yielding "electromer" $\mathbf{2}$ in Scheme 1. From 2

kinetics were recorded with a 1P28 photomultiplier (Hamamatsu). For a detailed description of the apparatus, see Ref. 11.

Conformational searches were performed with the MMFF molecular mechanics force field ${ }^{[12]}$ as implemented in the Spartan program. The quantum chemical calculations were performed with Gaussian 09 ${ }^{[13]}$ using the M06-2X DFT functional ${ }^{[14]}$ together with the $6-31 \mathrm{G}^{*}$ basis set. The choice of M06-2X was motivated by the better mid-range correlation description of this method compared to the standard B3LYP method. Furthermore, it has only a slightly larger computing cost than B3LYP, but is much less demanding in computational resources than double hybrid functionals like B2-PLYP ${ }^{[15]}$ which should be more accurate, but is difficult to use on molecules of the size of our model tripeptide. In one case, B2-PLYP was, however, used with the cc-pVDZ basis set to compare this method to M06-2X. The structures and the molecular orbitals were visualized with the MOplot ${ }^{[16]}$ and the ChemBio3D Ultra 12 programs. ${ }^{[17]}$ For the estimation of the strength of the interaction between the aromatic radical cations and the backbone amides, the calculations were corrected for the basis set superposition error (BSSE) using the Counterpoise method ${ }^{[18]} \mathrm{im}$ -

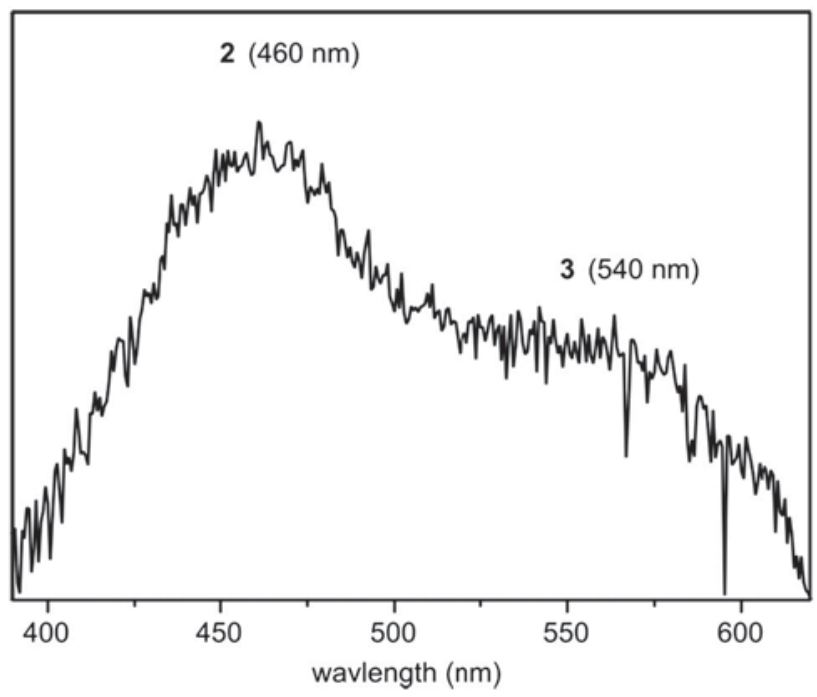

Figure 1. Experimentally observed transient electronic absorption spectrum of $\mathbf{2}$ and $\mathbf{3}, 40 \mathrm{~ns}$ after the laser pulse the electron hole can be transmitted, directly or via the central proline, to the more distant phe $(\mathrm{OMe})_{3}$ moiety to give electromer 3, and back. After equilibration we therefore have a mixture of $\mathbf{2}$ and $\mathbf{3}$, the composition of which we can assess by virtue of their different transient absorption spectra, $\lambda_{\max }=460 \mathrm{~nm}$ for 2 and $540 \mathrm{~nm}$ for 3 (see Fig. 1). ${ }^{[20]}$

Under our experimental conditions these aryl radical cations survive for about $100 \mu \mathrm{s}$, and we observed an equilibrium ratio of $65: 35$ within the $40-2000$ ns time scale of the laser experiment (Fig. 1). This was surprising because, in an equilibrium between the radical cations of the amino acids, di- or trimethoxyphenylalanine, the ratio of the two radical cations was found to be 40:60, in accord with the fact that phe $(\mathrm{OMe})_{3}$ is ca $10 \mathrm{mV}$ easier to oxidize that the phe $(\mathrm{OMe})_{2} \cdot{ }^{[4,19 \mathrm{~b}]}$ Thus, it seems that in our model peptide, the phe $(\mathrm{OMe})_{2}$ moiety that is attached to the $\mathrm{C}$-end of the proline seems to enjoy a special stabilization which overrides the inherent thermodynamic bias in favor of the ionized phe $(\mathrm{OMe})_{3}$ moiety.

This finding calls for an explanation which we sought by carrying out molecular mechanics and quantum chemical calcula-

Table 1. Relative energies and localization of the spin in the different conformers of 1

Conformer Neutral Radical cation Localization of the $\Delta \mathrm{E}(\mathrm{kcal} / \mathrm{mol}) \Delta \mathrm{E}(\mathrm{kcal} / \mathrm{mol}) \quad \mathrm{SOMO}(\mathrm{spin})^{\mathrm{a})}$

$\begin{array}{llll}\text { A } & 0.0 & 0.0 & \mathbf{2} \\ \mathbf{B} & 6.6 & 0.7 & \mathbf{3} \\ \mathbf{C} & 1.6 & 2.6 & \mathbf{2} \\ \mathbf{D} & 1.1 & 2.8 & \mathbf{2} \\ \mathbf{E} & 3.5 & 3.1 & \mathbf{2} \\ \mathbf{F} & 4.2 & 3.2 & \mathbf{2} \\ \mathbf{G} & 0.1 & 4.1 & \mathbf{2} \\ \mathbf{H} & 0.7 & 4.1 & \mathbf{2} \\ \mathbf{I} & 3.0 & 4.6 & \mathbf{2} \\ \mathbf{J} & 9.7 & 4.9 & \mathbf{3} \\ \mathbf{K} & 1.4 & 6.6 & \mathbf{3} \\ \mathbf{L} & 2.0 & 6.7 & \mathbf{2} \\ \text { a } & & \end{array}$




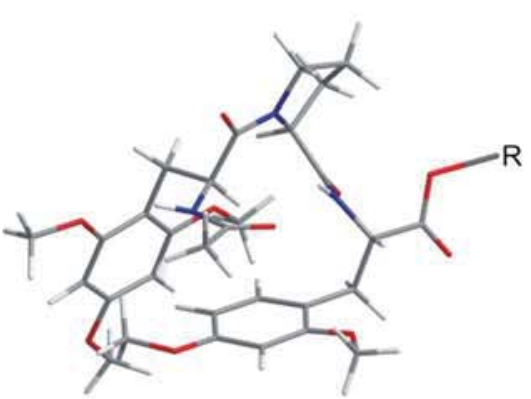

A

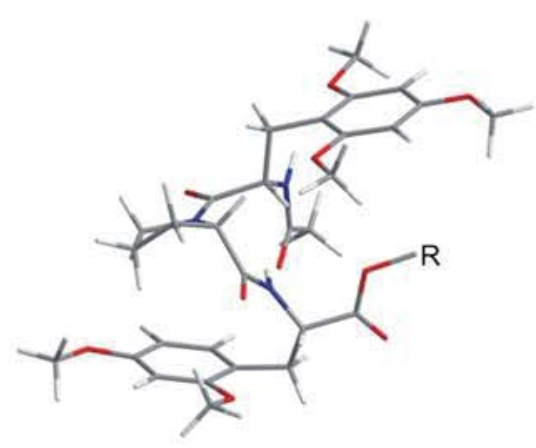

D

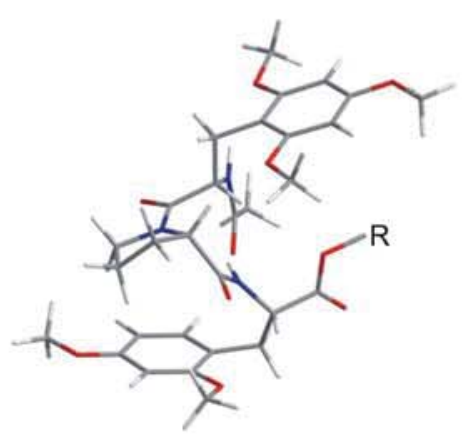

G

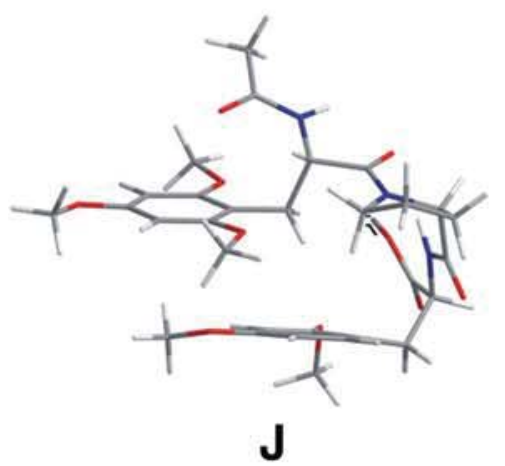

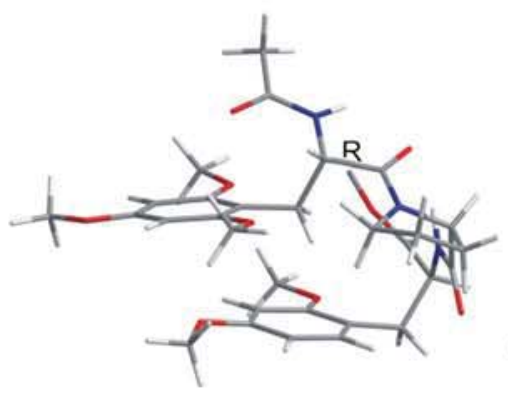

B

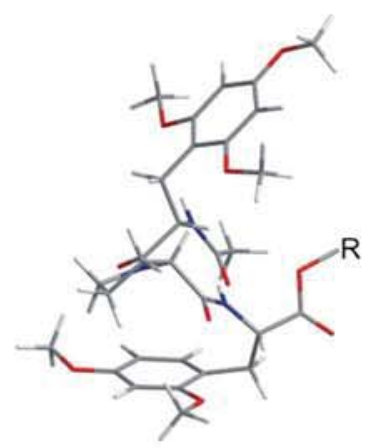

E

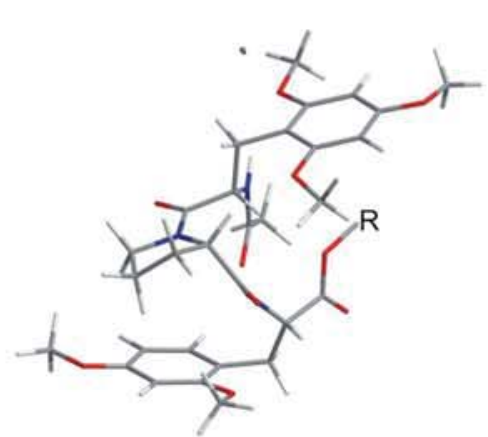

H

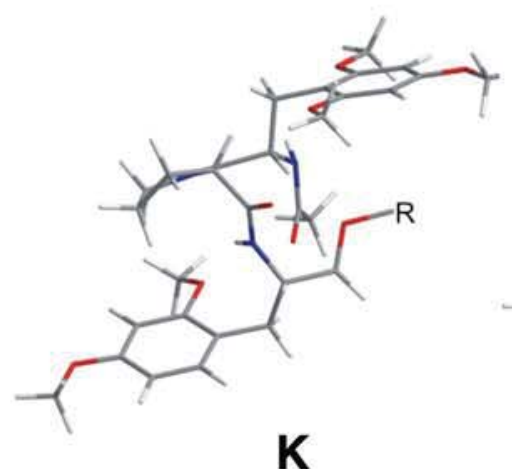

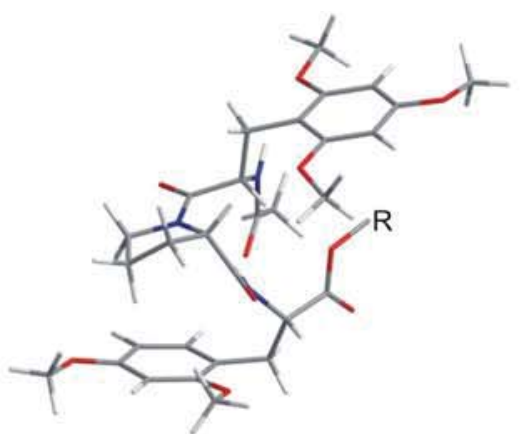

C

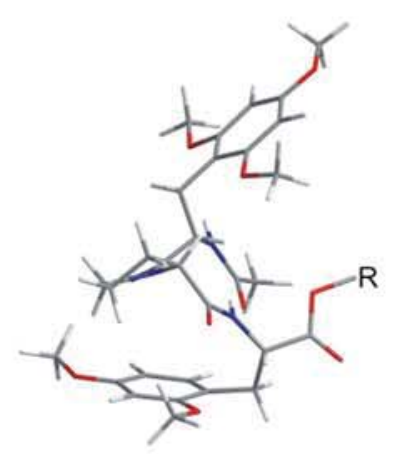

F

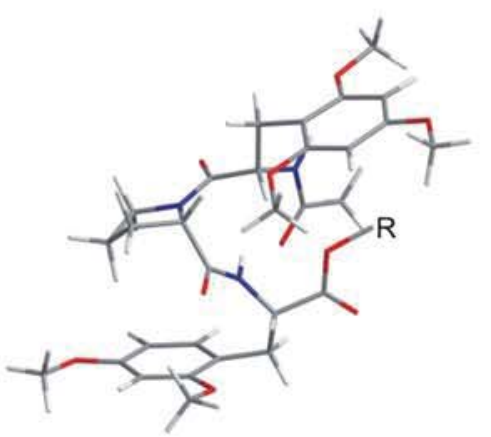

I

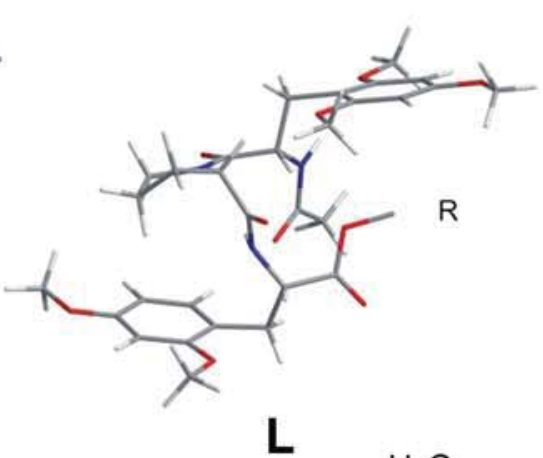

$R: \stackrel{\mathrm{H}_{2} \mathrm{C}}{\mathrm{O}} \underset{\mathrm{O}}{\mathrm{P}}$

Figure 2. Optimized conformers of the radical cation of $\mathbf{1}$ that were examined. Their relative energies are given in Table 1 
tions. In a first step, we subjected the neutral peptide $\mathbf{1}$ to a comprehensive conformational search with the MMFF force field, a search which yielded hundreds of conformers within $20 \mathrm{kcal} / \mathrm{mol}$ of the most stable one. From those we selected the 10 lowest energy conformers, ${ }^{[21]}$ in addition to two higher-lying ones ( $\mathbf{B}$ and $\mathbf{J}$ ) where we expected a stabilizing $\pi-\pi$ interaction between the two aromatic groups to prevail after one electron oxidation. ${ }^{[22]}$ These twelve conformers $\mathbf{A}-\mathbf{L}$ were reoptimized, before and after removing an electron, using the M06-2X/6-31G* DFT method (Table 1 and Fig. 2). ${ }^{[23]}$

The data in Table 1 show that in nine of these twelve conformers, including the most stable one (A), the unpaired electron (and much of the charge) is indeed localized on the dimethoxybenzyl moiety, in accord with the experimental finding that electromer $\mathbf{2}$ is predominant (Fig. 1). ${ }^{[23]}$ In what follows, the different conformers of the radical cation of the tripeptide will be denoted by the capital letters used in Table 1 and Fig. 2, preceded by $\mathbf{2}$ and $\mathbf{3}$ for the electro-mers where spin and charge are centered mainly on the di- or the trimethoxybenzyl moiety, respectively (cf. Scheme 1).

Inspection of the three most stable conformers, 2A, 3B and $\mathbf{2 C}$, reveals that their singly occupied molecular orbitals (SOMOs), which describe the distribution of the unpaired electron and hence the electron hole, are mostly localized on one of the aryl groups, with some delocalization into the amide backbone. In 2A the ionized aryl group interacts through space with the $\mathrm{N}$ terminal acetamide group, whereas in $\mathbf{3 B}$ and $\mathbf{2} \mathbf{C}$ the interaction is with the proximate amide group, partly through space (with the $\mathrm{p}-\mathrm{AO}$ of the oxygen atom in $\mathbf{3} \mathbf{B}$, with that of the nitrogen atom in $\mathbf{2 C}$ ), and partly through bond, by extension of the $\pi$ SOMO into the $\mathrm{C}-\mathrm{C}_{\alpha}$ bond connecting the phe $(\mathrm{OMe})_{2}$ moiety with the peptide backbone (see Fig. 3).

The stabilizing effects of these amide- $\pi$ interactions lower the ionization energies (IE) of the tripeptide 1 compared to di- or trimethoxytoluene. The calculated IE of the neutral conformer $\mathbf{1 A}$ is $10.6 \mathrm{kcal} / \mathrm{mol}$ lower than that of $2,4-$ dimethoxytoluene, where-as the energy gain for $\mathbf{1 B}$ relative to trimethoxytoluene is only $3.2 \mathrm{kcal} / \mathrm{mol}$ (see Table $\mathrm{S} 1$ in

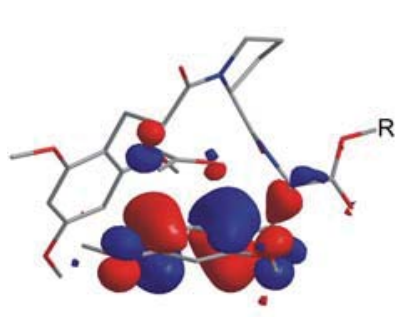

$2 \mathrm{~A}$

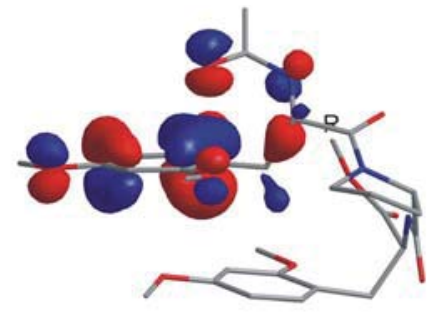

3B

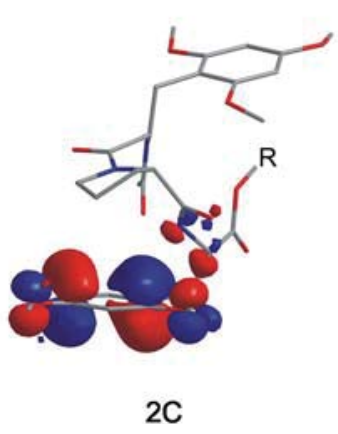

Figure 3. SOMOs of the three lowest energy conformers of the radical cation $\mathbf{2 A}, \mathbf{3 B}$ and $\mathbf{2 C}$. The hydrogen atoms have been deleted for clarity the Supporting Information). Surprisingly, in conformer 3B, which is predisposed for a stabilizing through-space $\pi-\pi$ interaction between the two aromatic rings, the SOMO barely extends to the dimethoxytoluene moiety, and the two aromatic rings remain roughly at their van-der-Waals distance (see Fig. S1 in the Supporting Information).

Thus, the interaction with the terminal amide group apparently provides more stabilization to the ionized phe $(\mathrm{OMe})_{3}$ moiety than that with the proximate aromatic ring. The through-space interaction between the amide and the aromatic group manifests itself also in a marked decrease of the distance between the two moieties upon one electron oxidation (see Fig. S2 in the Supporting Information). In conformers $\mathbf{A}$ and $\mathbf{C}$, this distance decreases by about $0.2 \AA$, whereas in $\mathbf{B}$ the decrease is almost $0.7 \AA$.

To estimate the strength of the dimethoxybenzyl/amide interaction, the dissociation energy of a radical cation complex between $\mathrm{N}$-methylacetamide and dimethoxytoluene was calculated, using the geometry that was found for the respective functional groups in the most stable conformer $\mathbf{2 A}$ (green structures in Fig. 4). The resulting dissociation energy was found to be $11.5 \mathrm{kcal} / \mathrm{mol}$ with $\mathrm{M} 06-2 \mathrm{X} / 6-31 \mathrm{G}^{*}$, and $11.1 \mathrm{kcal} / \mathrm{mol}$ with B2PLYPD/cc-pVDZ. After geometry reoptimization of the complex, the dissociation energy increased by only $1.5 \mathrm{kcal} / \mathrm{mol}$ which indicates that, in conformer $\mathbf{2 A}$, the orientation of the amide group relative to the aromatic ring is almost optimal for the stabilization of the radical cation. ${ }^{[24]}$

To explain the apparent "counterthermodynamic" ratio between $\mathbf{2}$ and $\mathbf{3}$ found experimentally and computationally, further calculations were done on four different species, $\mathbf{2 A}$ and $\mathbf{2 C}$ where the electron hole is localized on the dimethoxybenzyl group, and $\mathbf{3 B}$ and $\mathbf{3} \mathbf{K}$ with a trimethoxybenzyl centered radical cation. In these four conformers, the phe $(\mathrm{OMe})_{2}$ was exchanged with the phe $(\mathrm{OMe})_{3}$ group. After geometry reoptimization, the (former) conformers $\mathbf{2 A}$ and $\mathbf{2 C}$ had the SOMO localized on the trimethoxybenzyl group, as expected from thermodynamics. However, after the exchange of the two aromatic groups in $\mathbf{3 B}$ and $\mathbf{3} \mathbf{K}$, the spin was localized on the dimethoxybenzyl group. From this we conclude that what matters is not really the nature of the aromatic group but rather its position within the peptide.

The methoxyaryl groups that carry the unpaired electron were superimposed for all four conformers (Fig. 5 where only the parts of the tripeptide which carry non-negligible spin density are shown). For the conformers where the spin is localized on the

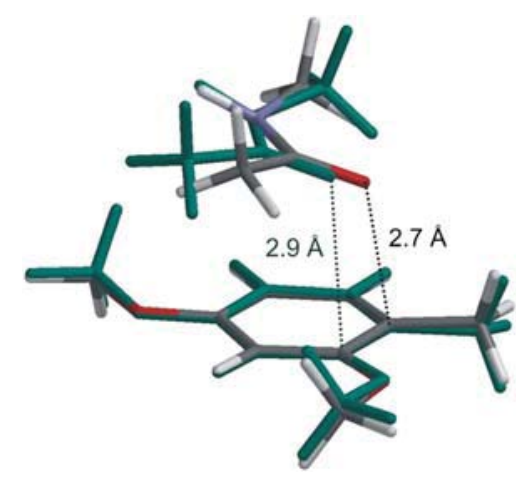

Figure 4. Model system used to evaluate the strength of the amidedimethoxybenzyl interaction. The green structure represents the conformation $\mathbf{2 A}$, and the other is the geometry optimized structure of the complex 

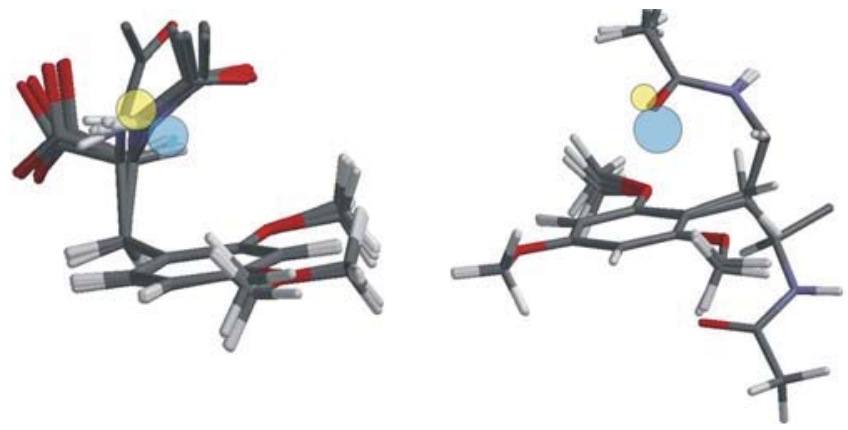

Figure 5. Superimposition of the conformers of $\mathbf{2}$ and $\mathbf{3}$ having the spin localized on the dimethoxybenzyl (left) or on the trimethoxybenzyl (right) with the interacting lone pair depicted in transparency

dimethoxybenzyl moiety, the orientation of the neighboring amide relative to the aromatic group is similar, in that the lone pair of the nitrogen atom (indicated schematically in Fig. 5) points towards the aromatic ring. The only exception is conformer $\mathbf{2 A}$ where the aromatic centered radical cation is interacting with the N-terminal methylacetamide (not shown in Fig. 5).

In the conformers where the spin is localized on the trimethoxybenzyl moiety, the p-lone pair of the oxygen atom of the N-terminal methylacetamide (cf. Fig. 5, right hand side) is mainly responsible for the stabilizing interaction but, because the $\mathrm{O}$-atom of the methylacetamide is more distant from the aromatic ring than the $\mathrm{N}$-atom, the $\mathrm{N} / a r y l$ is more favorable than the O/aryl interaction, which could explain the 2:3 ratio observed and calculated. Furthermore, the rigidity of the central proline unit makes it very unlikely that the nitrogen p-lone pair of the $\mathrm{N}$-terminal methylacetamide could interact with the trimethoxybenzyl moiety.

Finally, calculations on the "natural" tripeptide PheProPhe (4) were carried out, starting from the conformations $\mathbf{2 A}$, 3B and $\mathbf{2 C}$, removing the methoxy groups, and replacing the "charge injector" group R in Fig. 1 by a methyl group. After geometry optimization, conformers $\mathbf{4 A}$ and $\mathbf{4 B}$ were found to have a spin distribution similar to that of the corresponding tripeptide containing methoxy groups except that the odd electron is more delocalized into the peptide backbone because the electron donating groups which stabilized the hole were removed from the aromatic rings. In $\mathbf{2 A}$, the phe $(\mathrm{OMe})_{2}$ group carries $93 \%$ of the spin against $77 \%$ for phenylalanine in $\mathbf{4 A}$. In $\mathbf{3 B}, 85 \%$ of the spin is localized on the trimethoxybenzyl group, but it is only $69 \%$ in the corresponding phenylalanine of $4 \mathrm{~B}$ (see Table 2 and Fig. S3). Interestingly, in $\mathbf{4 B}$ the spin is more noticeably delocalized into the other aromatic ring than in $\mathbf{3 B}$.

Surprisingly, in conformers $\mathbf{2 C}$ to $\mathbf{2 l}$, stripped of all methoxy groups, the spin was found to be largely localized in the $\mathrm{N}-\mathrm{C}_{\alpha}-\mathrm{C}=\mathrm{O}$ portion of the proline unit (see Table 2 and Fig. 6 ). The SOMO of $\mathbf{4 C}$ clearly shows that in this conformation the $\mathrm{N}$ lone pair undergoes strong through-bond interaction with the in-plane p-lone pair on the $\mathrm{O}$ atom via the connecting $\mathrm{C}_{\alpha}-\mathrm{C}$ $(=0)$ bond. Because of the conformational constraints of the proline this $\mathrm{C}-\mathrm{C}$ bond adopts a favorable orientation for this hyperconjugation already in the neutral. This effect reduces the ionization potential of the neutral peptide, compared to toluene, by $10.3 \mathrm{kcal} / \mathrm{mol}$ (see Table S1).

Until now it has usually been assumed that a charge (or an unpaired electron) that is localized on the backbone of an ionized peptide, resides in the nonbonding (heteroallylic) $\pi$-MO of an amide unit. Charge transport in peptides has been modeled on

\begin{tabular}{|c|c|c|c|c|}
\hline Species & $\begin{array}{l}\text { C-terminal aryl } \\
\text { group }\end{array}$ & $\begin{array}{l}\mathrm{N} \text {-terminal } \\
\text { amide }\end{array}$ & $\begin{array}{l}\text { Amide next } \\
\text { to aryl group }\end{array}$ & Sum \\
\hline $2 A$ & 0.93 & 0.03 & 0.02 & 0.98 \\
\hline \multirow[t]{2}{*}{ 4A } & 0.77 & 0.09 & 0.13 & 0.99 \\
\hline & $\begin{array}{l}\text { C-terminal } \\
\text { aryl group }\end{array}$ & $\begin{array}{l}\mathrm{N} \text {-terminal } \\
\text { aryl group }\end{array}$ & $\begin{array}{l}\mathrm{N} \text {-terminal } \\
\text { amide group }\end{array}$ & \\
\hline 3B & 0.02 & 0.85 & 0.12 & 0.99 \\
\hline \multirow[t]{2}{*}{ 4B } & 0.09 & 0.69 & 0.21 & 0.99 \\
\hline & $\begin{array}{c}\text { Amide } \\
\text { backbone }\end{array}$ & Proline & $\begin{array}{l}\text { C-terminal aryl } \\
\text { group }\end{array}$ & \\
\hline $2 \mathrm{C}$ & 0.02 & 0.00 & 0.97 & 0.99 \\
\hline $4 C$ & 0.95 & 0.04 & 0.00 & 0.99 \\
\hline
\end{tabular}

the basis of this assumption. However, Gil et al. have pointed out in 2008 , based on the study of the model compounds HCO-Gly- $-\mathrm{NH}_{2}$ and $\mathrm{HCO}$-ala- $\mathrm{NH}_{2}$, that other states of ionized peptides may be more stable than the above ones. ${ }^{[25]}$ In one of these states, the in-plane $\mathrm{p}$-AOs of the carbonyl groups of two neighboring peptide units form a $2 \mathrm{c}-3 \mathrm{e}$-bond. This was discussed in detail by the group of $\mathrm{Bu}_{1}{ }^{[26]}$ and identified by Schlag et al. as being responsible for the transfer of spin and charge between neighboring peptidic units. ${ }^{[27]}$ Another state corresponds to that shown for 4 C in Fig. 6, where the spin is delocalized over an $(\mathrm{O}=\mathrm{C}) \mathrm{N}-\mathrm{C}_{\alpha}-\mathrm{CO}$ unit.

In order to assess the relative energies of such states we synthesized a small model compound, $\mathrm{N}$-acetylproline dimethylamide $\mathbf{5}$, measured its photoelectron (PE) spectrum, and compared it to that of dimethylacetamide (DMA) (Fig. 7). ${ }^{[28]}$ An analysis based on (TD)DFT calculations reveals that the first band in the PE spectrum of DMA contains ionizations from two close-lying MOs, the first from the nonbonding $\pi-\mathrm{MO}$ of the amide unit, followed by that from the in-plane p-AO of the carbonyl oxygen (cf. MOs deppicted in Fig. 7).

The first vertical ionization potential of $\mathbf{5}$ is ca $0.4 \mathrm{eV}$ lower than that of DMA, indicating a strong stabilization of the radical cation. According to calculations, the first broad band comprises four ionizations, ${ }^{[29]}$ the lowest of which arises indeed by the removal of an electron from a molecular orbital very similar to that depicted for $\mathbf{4 C}$ in Fig. $\mathbf{6}$. The most stable conformation of neutral $\mathbf{5}$ was in fact found to be very close to the optimal one for through-bond interaction of the lone pair on the proline $\mathrm{N}$ atom
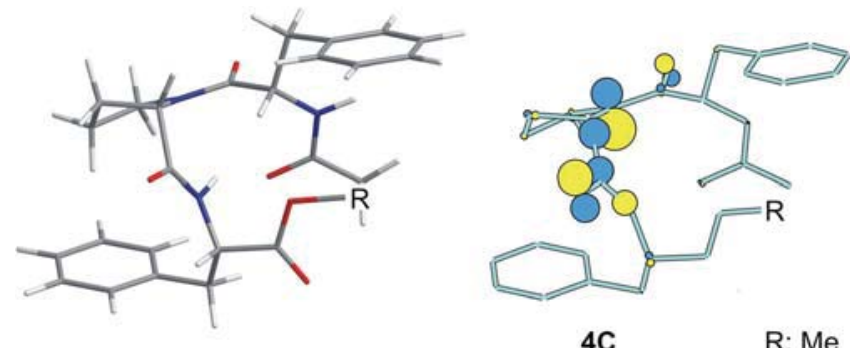

Figure 6. SOMO of conformer $\mathbf{4 C}$ that corresponds to the conformer $\mathbf{2 C}$ without the methoxy groups (it has a cis Pro-Phe linkage because of its derivation from $\mathbf{2} \mathbf{C}^{[21]}$ ) 


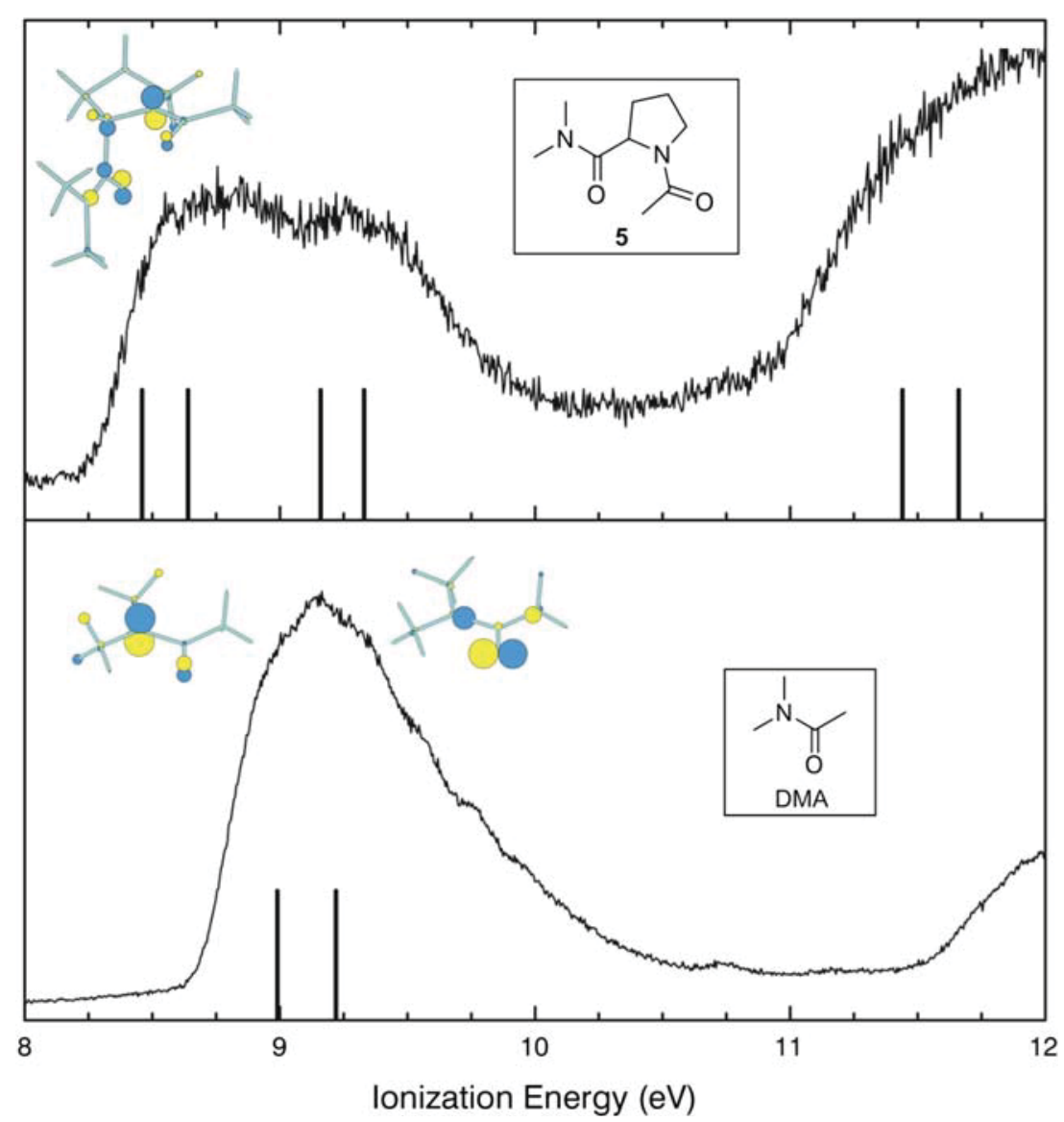

Figure 7. Photoelectron spectrum of $\mathrm{N}$-acetylproline dimethylamide $\mathbf{5}$ juxtaposed to that of dimethylacetamide (DMA). Black bars denote results of (TD)DFT calculations (see Table S2 in the Supporting Information)

and the in-plane lone pair of the other carbonyl group in the radical cation. It is for this reason that the ionization energy of $\mathbf{5}$ is noticeably lowered relative to that of DMA. The next state is formed by removal of an electron from the nonbonding heteroallylic orbital which corresponds to the HOMO in DMA, while the remaining two states are associated with from linear combinations of the in-plane p-AOs of the two oxygen atoms.

The state where the in-plane $\mathrm{p}$-AOs of the carbonyl groups of two neighboring peptide units form a $2 \mathrm{c}-3 \mathrm{e}$-bond is not found here because no such state is accessible by vertical ionization of the neutral conformers. However, by a modification of the $(\mathrm{O}=\mathrm{C})$ $\mathrm{N}-\mathrm{C}_{\alpha}-\mathrm{CO}$ dihedral angle of the radical cation, one can fall into this particular electronic state. In fact, the states of peptide radical cations where the electron hole is delocalized over a $(\mathrm{O}=\mathrm{C})$ $\mathrm{N}-\mathrm{C}_{\alpha}-\mathrm{CO}$ moiety could be accessible in the course of hole transfer along peptides and may play the role of stepping stones. In polyprolines these states are readily accessible because the dihedral angles which maximize the through-bond interaction of the $\mathrm{N}$ lone pair with the in-plane $\mathrm{p}-\mathrm{AO}$ of the oxygen of the next peptide unit are close to their optimal values. The properties of these states, and whether they generally play a role in the hole transfer in peptides will be explored in a forthcoming publication.

\section{CONCLUSION}

The influence of proline in the localization of a radical cation in a model tripeptide composed of a tri- and a dimethoxy substituted phenylalanine linked by a proline was studied by flash photolysis and DFT calculations.

Surprisingly, the experiments showed that, at equilibrium, $65 \%$ of the tripeptide radical cations have the electron hole localized on the dimethoxybenzyl moiety, although this is more difficult to oxidize than its dimethoxyphenyl counterpart. This observation was explained with the help of calculations which showed that the radical cation is not only stabilized by the electron donating effect of the methoxy groups, but also by interaction with the p-lone pair of a proximate amide group. The strength of this amide/aromatic interaction in the peptide radical cation was estimated to be ca $11 \mathrm{kcal} / \mathrm{mol}$, which amounts to twice the difference between the ionization energies of di- and trimethoxytoluene. Interestingly, even for conformers where a stabilizing $\pi-\pi$ interaction between the two aromatic rings would be possible, the amide- $\pi$ interaction is preferred. It turns out that a majority of the conformers have the spin localized on the dimethoxybenzyl group because it is interacting with the $\mathrm{p}$-lone pair of the neighboring nitrogen atom, which is closer to the aromatic group than the $\mathrm{p}$-lone pair of oxygen that interacts with the trimethoxybenzyl moiety.

The absence of OMe-substituents at the aromatic side chains leads to a stronger stabilization of the radical cation at the peptide backbone. In several conformations of the natural tripeptide PheProPhe the hole is almost exclusively delocalized over the two peptide groups. This is made possible by the through-bond interaction of the $\mathrm{p}$-lone pairs of the $\mathrm{N}$ and the O-atoms of each amino acid which prevails if these 
two lone pairs are antiperiplanar and lie in the same plane as the $\mathrm{C}_{\alpha}-\mathrm{C}(=0) \sigma$-bond linking them (see structure $4 \mathrm{C}$ in Fig. 6). As in proline the $\mathrm{N}$-lone pair is already antiperiplanar to the $\mathrm{C}_{\alpha}-\mathrm{C}(=\mathrm{O}) \sigma$-bond by design, a conformation where the inplane $\mathrm{p}$ lone pair of the oxygen atom is also antiperiplanar to that bond is more readily achieved than in open-chain peptide units where free rotation is possible around both Ramachandran angles. The state of the radical cation where the unpaired electron resides in such a "hyperconjugated" $\sigma$ $\mathrm{MO}$ lies ca $0.5 \mathrm{eV}$ below the ground state of the dimethylacetamide radical cation, where the unpaired electron sits in a nonbonding heteroallylic $\sigma-\mathrm{MO}$.

Thus one should consider such "hyperconjugated amide groups" as potential relay stations in the electron transfer of polypeptides, which carry no electron-rich side groups that can serve as "stepping stones" for electron hole transfer through proteins. Due to its rigidity, the chance to attain a conformation that allows for efficient hyperconjugation is higher in proline than in open-chain amino acids; thus, proline is more likely to foster electron hole transfer.

\section{Acknowledgements}

The authors wish to thank the Swiss National Foundation SNF for the financial support (Grant No. 200020_143410). We are very indebted to Prof. Michael Allan (University of Fribourg) for letting us use his photoelectron spectrometer, and to his graduate student, Khrystyna Regeta, for measuring the spectra shown in Fig. 7. We thank Dr. Matthias Messerer for the synthesis of the $\mathrm{N}$-acetylproline dimethylamide.

\section{REFERENCES}

[1] For reviews see: a) J. Stubbe, D. G. Nocera, C. S. Yee, C. Y. Yang Chem. Rev. 2003, 103, 2167; b) M. Cordes, B. Giese, Chem. Soc. Rev. 2009, 38, 892; c) B. Giese, S. Eckhardt, M. Lauz, in: Encyclopedia of Radicals in Chemistry, Biology and Materials, (Eds: C. Chatgilialoglu, A. Studer), Wiley, Chichester, 2012, 1475.

[2] a) R. A. Marcus, Angew. Chem. Int. Ed. Engl. 105, 1161; b) Angew. Chem. Int. Ed. Engl 1993, 32, 1111.

[3] H. B. Gray, J. R. Winkler, Chem. Phys. Lett. 2009, 483, 1.

[4] a) M. Cordes, A. Köttgen, C. Jasper, O. Jacques, H. Boudebous, B. Giese, Angew. Chem. Int. Ed. Engl. 2008, 47, 3461; b) J. Gao, P. Müller M. Wang, S. Eckhardt, M. Lauz, K. M. Fromm, B. Giese, Angew. Chem. Int. Ed. Engl. 2011, 50, 1926.

[5] a) The concept of the hopping mechanism is discussed in detail for long distance electron transfer through DNA; b) J. Jortner, M. Bixon, T. Langenbacher, M. E. Michel-Beyerle, Proc. Natl. Acad. Sci. USA 1998, 95, 12759. c) M. Bixon, B. Giese, S. Wessely, T. Langenbacher, M. E. Michel-Beyerle, J. Jortner, Proc. Natl. Acad. Sci. USA 1999, 96, 11713; d) B. Giese, M. Spichty, ChemPhysChem 2000, 1, 195.

[6] a) R. A. Malak, Z. Gao, J. F. Wishart, S. S. Isied, J. Am. Chem. Soc. 2004, 126, 13888. b)Y. Arikuma, H. Nakayama, T. Morita, S. Kimura, Angew. Chem. Int. Ed. Engl. 2010, 49, 1800.

[7] a) C. Shih, A. K. Museth, M. Abrahamsson, A. M. Blanco-Rodriguez, A. J. DiBilio, J. Sudhamsu, B. R. Crane, K. L. Ronayne, M. Towrie, A. Vleck, J. H. Richards, J. R. Winkler, H. B. Gray, Science 2008, 320, 1760; b) B. Giese, M. Wang, J. Gao, M. Stoltz, P. Müller, M. Graber, J. Org. Chem. 2009, 74, 3621; c) M. Wang, J. Gao, P. Müller, Angew. Chem. Int. Ed. Engl. 2009, 48, 4232; (d) M. Zhang, J. Zhao, H. Yang, P. Liu, Y. Bu, J. Phys. Chem. 2013, 117, 6385.

[8] a) R. S. Glass, G. L. Hug, C. Schöneich, G. S. Wilson, L. Kuznetsova, T.-M. Lee, M. Amman, E. Lorance, T. Nauser, G. S. Nichol, T. Yamamoto, J. Am. Chem. Soc. 2009, 131, 13791; b) R. S. Glass, C. Schöneich, G. S. Wilson, T. Nauser, T. Yamamoto, E. Lorance, G. S. Nichol, M. Ammam, Org. Lett. 2011, 11, 2837; c) W. J. Chung, M. Ammam, N. E. Gruhn, G. S. Nichol, W. P. Singh, G. S. Wilson, R. S.
Glass, Org. Lett. 2009, 11, 397; d) N. P.-A. Monney, T. Bally, G. S Bhagavathy, R. S. Glass, Org. Lett. 2013,15, 4932.

[9] a) X. Chen, L. Zhang, L. Zhang, W. Sun, Z. Zhang, H. Liu, Y. Bu R. I. Cukier, J. Phys. Chem. Lett. 2010, 1, 1637; b) M. Lauz, S. Eckhardt, K. M. Fromm, B. Giese, Phys. Chem. Chem. Phys. 2012, 14, 1378 .

[10] M. Kuemin, S. Schweizer, C. Ochsenfeld, H. Wennemers, J. Am. Chem. Soc. 2009, 131, 15474.

[11] a) J. Wirz, Pure Appl. Chem. 1984, 56, 1289; b) E. Leyva, M. S. Platz, G. Persy, J. Wirz, J. Am. Chem. Soc. 1986, 108, 3783; c) S. Gerber, J. Wirz, EPA Newslett. 1989, 36, 1

[12] a) T. A. Halgren, J. Comput. Chem. 1996, 17, 490-519; b) T. A. Halgren, R. B. Nachbar, J. Comput. Chem. 1996, 17, 587-615.

[13] Gaussian 09, Revision C.01., M. J. Frisch et al., Gaussian, Inc., Wallingford CT, 2009. (full citation given in the Supporting Information).

[14] Y. Zhao, D. G. Truhlar, Acc. Chem. Res. 2008, 41, 157.

[15] F. Neese, S. Grimme, J. Chem. Phys. 2007, 126, 124115.

[16] R. V. Olkhov, T. Bally, MOPlot v.1.86., http://www-chem.unifr.ch/tb/ moplot/moplot.html (last visit 07.15.2014)

[17] ChemBio3D ultra 12. http://www.cambridgesoft.com/Ensemble_ for_Chemistry/ChemBio3D/Default.aspx (last visit 07.15.2014)

[18] S. F. Boys, F. Bernardi, Mol. Phys. 1970, 19, 553-566.

[19] For the synthesis of the charge injecting system and the mechanism of the charge generation see: a) B. Giese, M. Napp, O. Jaques, H Boudebous, A. M. Taylor, J. Wirz, Angew. Chem. Int. Ed. 2005, 44, 4073; b) B. Giese, S. Kracht, M. Cordes, CHIMIA 2013, 67, 855.

[20] This assignment was confirmed by the separate measurements of the 2,4-di- and 2,4,6-trimethoxyphenylalanine radical cations at known concentrations (M. Cordes, O. Jacques, A. Köttgen, C. Jasper, H. Boudebous, B. Giese, Adv. Synth. Catal. 2008, 350, 1053.)

[21] We were suprised to see that the 10 lowest energy conformers of neutral 1 all had cis Pro-Phe amide linkages, while the Phe-Pro linkages are trans (the two higher lying ones, $\mathbf{B}$ and $\mathbf{J}$ have trans linkages). We do not know what factors are responsible for overriding the slight preference for trans over cis amide linkages in prolines in $\mathbf{1}$, but this result does not affect the conclusions of this paper.

[22] Indeed, such interactions are well known and described and should be considered in our model tripeptide. See, e.g.: B. Badger, B. Brocklehurst, Trans. Faraday Soc. 1969, 65, 2582-2587.

[23] We would like to emphasize that no systematic search of all conformers of ionized $\mathbf{1}$ was carried out, so we do not claim any quantitative significance for this number, although no bias in favor of one or the other oxidation site was introduced.

[24] The stabilization experienced by the trimethoxybenzene radical cation in 3B cannot be calculated similarly, because, in contrast to $\mathbf{2 A}$, the amide is linked to the aromatic part by a $\mathrm{C}-\mathrm{C}$ bond which provides substantial through-bond interaction between the two moieties (see Fig. 3), an interaction that is lost if one separates the two moieties.

[25] A. Gil, M. Sodupe, J. Bertran, J. Comput. Chem. 2008, 30, 1771.

[26] X. Chen, L. Zhang, Z. Wang, J. Li, W. Wang, Y. Bu, J. Phys. J. Phys. Chem. 2008, 112, 14302-14311.

[27] see, e.g. E. W. Schlag, S.-Y. Sheu, D.-Y. Yang, H. Selzle, S. H. Lin Angew. Chem. Int. Ed. 2007, 46, 3196.

[28] The spectrum of DMA has been published previously (D. A Sweigart, D. W. Turner, J. Am. Chem. Soc. 1972, 94, 5592). We confirmed the values obtained there.

[29] Actually, compound $\mathbf{5}$ is composed of two conformations which contribute almost equally and make up over $95 \%$ of the conformational ensemble. These two species differ by the conformation of the proline ring (see Fig. S4 in the Supporting Information), but the calculations predict that their cationic state energies differ by less than $0.01 \mathrm{eV}$, because the orbitals from which ionizations occur do not involve the proline ring.

\section{SUPPORTING INFORMATION}

Additional supporting information may be found in the online version of this article 